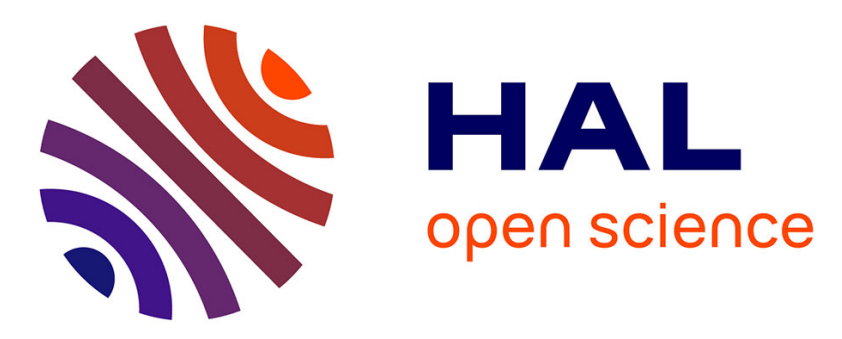

\title{
First-principles density functional theory study of strained wurtzite InP and InAs
}

\author{
Chahira Hajlaoui, Laurent Pedesseau, Faical Raouafi, F. Ben Cheikhlarbi, \\ Jacky Even, Jean-Marc Jancu
}

\section{To cite this version:}

Chahira Hajlaoui, Laurent Pedesseau, Faical Raouafi, F. Ben Cheikhlarbi, Jacky Even, et al.. Firstprinciples density functional theory study of strained wurtzite InP and InAs. Journal of Physics D: Applied Physics, 2013, 46 (50), pp.505106. 10.1088/0022-3727/46/50/505106 . hal-00920126

\section{HAL Id: hal-00920126 https://hal.science/hal-00920126}

Submitted on 10 Mar 2014

HAL is a multi-disciplinary open access archive for the deposit and dissemination of scientific research documents, whether they are published or not. The documents may come from teaching and research institutions in France or abroad, or from public or private research centers.
L'archive ouverte pluridisciplinaire HAL, est destinée au dépôt et à la diffusion de documents scientifiques de niveau recherche, publiés ou non, émanant des établissements d'enseignement et de recherche français ou étrangers, des laboratoires publics ou privés. 


\title{
First-principles density functional theory study of
}

\section{strainedwurtziteInP and InAs}

C. Hajlaoui ${ }^{1,2}$, L. Pedesseau ${ }^{1}$, F. Raouafi ${ }^{2}$, F. Ben CheikhLarbi ${ }^{2}$, J.Even ${ }^{1}$, and J.-M. Jancu ${ }^{1 *}$ ${ }^{1}$ Université Européenne de Bretagne, INSA, FOTON, UMR 6082, 35708 Rennes, France

${ }^{2}$ Laboratoire de physico-chimie, des microstructures et des micro-systèmes, Institut Préparatoire aux Études Scientifiques et Techniques, Université de Carthage, BP51, 2070 La Marsa, Tunisie

\begin{abstract}
.
We report onsemilocal and hybriddensity functional theory (DFT) studyof strainedwurtzitecrystals of InAs and InP. The crystal-field splitting has a large and non-linear dependence on strain for both crystals.Moreover, the study of the electronic deformation potentials reveals that the well-known quasi-cubic (QC) approximation fails to reproduce the non-ideal $c / a$ ratio. This theoretical study is of crucial importance for the simulation of self-assembled InAs/InP nanowires.
\end{abstract}

*Corresponding author: jean-marc.jancu@insa-rennes.fr 
Semiconductor core/shellnanowires $(\mathrm{NWs})^{1,2}$ hold lot of promises for applications in the field in electronics ${ }^{3,4}$,photonics ${ }^{5,6}$, and biochemical sensors. ${ }^{7}$ These systems, compared to pure semiconductor wires, demonstrate areductionof surface scattering and ionized impurity scattering ${ }^{8}$ with improved electronic confinement properties. The synthesis processis mainly based on the gold-catalyzed vapor liquid-solid (VLS) growth mechanisms, which allows for a precise controlof geometrical dimensionsand strain accommodation. ${ }^{9}$ The VLS method is particularly suited in interfacing highly strained III-V materials onto $\mathrm{Si}$ substrates. ${ }^{10}$ Interestingly, it favors the hexagonal phase at the nucleation stage leading toa crystallization of III-V semiconductorsinahexagonal wurtzite (WZ) structure whereasthe bulk counterpart for most of them is cubic zinc-blende (ZB). ${ }^{11}$ Recently, much effort has been devoted to the growth and fabrication of strained InP/InAs/InPNW devices for the realizationof high field-effect electron mobility transistors and circuits. Advantages of thesesystems include the high electron mobility $\left(30000 \mathrm{~cm}^{2} / \mathrm{V} \mathrm{s}\right.$ at 300 $\mathrm{K})$ and velocity $(43000 \mathrm{~cm} / \mathrm{s})$ of InAsand a large conduction band offset between InAs and $\operatorname{InP}(0.5$ $\mathrm{eV}) .{ }^{12}$ Strain engineering is a well-established technique to tune the electronic band gap of nanostructures. For instance, the lattice mismatch ofInAs onInPis about $-3 \%$ and it is expected to tailor the band offsets and carrier mobility by lifting the degeneracy in the electronic bands. In addition, strain effects cangeneratea piezoelectric polarization charge at interfaces leading to a band bending in the active region of the wire.Determining thematerials properties ofInAs/InP NWs iskey to improving current generating efficiencies of underlying devices.The $\mathrm{WZ}$ and $\mathrm{ZB}$ band structuresfor bulk InAs and InPhave been extensively studied both theoretically and experimentally. ${ }^{12-14}$ Moreover, electronic deformation potentials (DPs) of cubic semiconductors are well documented in literature. ${ }^{12}$ However, to the best of our knowledge, no workon DPs has dealt withWZ III-V materials so far. This first step is mandatory for realistic modeling of InAs/InP NWs in the WZ structure ${ }^{15}$, including the effects of linear and non-linear electro-elastic coupling. ${ }^{16}$

In this work, we performab initio calculationsofdeformation potentials in wurtziteInAs and InP. The structural relaxations with strain perturbations are performed using the plane-wave 
projector augmented wave method (PAW) as implemented in the VASP code. ${ }^{17}$ We used the HeydScuseria-Ernzerhof (HSE06) DFT hybrid exchange correlation functional ${ }^{18,19}$ with a screening parameter $\mu=0.2$ and a mixing parameter of $\alpha=0.25$. This approach has been foundto give reliable resultsin group III-nitrides ${ }^{20}$ and group II-oxides. ${ }^{21}$ Generalized-Gradient Approximation (GGA) in the Perdew-Burke-Ernzerhof (PBE) parameterization ${ }^{22}$ and single shot $\mathrm{GW}\left(\mathrm{G}_{0} \mathrm{~W}_{0}\right)$ calculations implemented in VASP are also performed for comparison. We used GGA eigenvalues as input to the single shot $\mathrm{G}_{0} \mathrm{~W}_{0}$ calculations leading to more reliable parameters such as band gap and deformation potentials. The semi-core $d$-electrons of Inaretreated as valence electrons. The procedure is carried out with a plane-wave cutoff of $600 \mathrm{eV}$ and a $6 \times 6 \times 4$ Monkhorst-Pack mesh for k-point sampling. This allows for a full relaxationof the structural parameters. The accuracy of the predicted equilibrium lattice constants for both InP and InAscorrelates directly with the level of approximation in the functional as shown in Table I. HSE gives the most accurate resultsandthe well-known overcorrection ofGGA-PBE ${ }^{23}$ become apparent. We also note in Tab. Ithat the WZstructure is not perfectly tetrahedral with non-ideal $c / a$ and $u$ (an ideal WZ lattice consists ina tetragonal ratio $c / a=1.633$ of the lattice constants and an ideal internal cell parameter $u=3 / 8$ )as found for bothsimulations and experiment.

Fig. 1 shows the InAs and InPband structures at equilibrium near the $\Gamma$-point computed with HSE. Calculations are performed without spin-orbit coupling. The direct band gap is formed by an s-like $\Gamma_{1 c}(B C)$ conduction-band state and doubly degenerate p-like $\Gamma_{6 \mathrm{v}}(H H, L H)$ and $\Gamma_{l v}(\mathrm{CH})$ valence-band states. Two energy gaps can be defined according to the optical transitions: $\Gamma_{6 \mathrm{v}} \rightarrow \Gamma_{1 \mathrm{c}}(A, B)$ and $\Gamma_{1 \mathrm{v}} \rightarrow \Gamma_{1 \mathrm{c}}(C)$. In our simulations, $E_{A / B}$ is the fundamental transition energyforboth InAs and InP. As evidenced in Fig. 1, away from the Brillouin zone-center,the valence bands are strongly admixed and their dispersion is non-parabolic. Therefore the valenceband effective massescannot be easily derived for application in k.p models. On the other hand, the conduction band energy dispersionis parabolic near the $\Gamma$-point and ourHSEcalculation of the electron masses perpendicular and parallel to the $c$-axis gives: 0.055 and 0.032 (in units of free 
electron mass).These results are consistent with thoseof De and Prior obtained within an empirical pseudopotentialapproach. ${ }^{24}$ As seen in Tab. I, the band-gap energy issensitive to the details of the exchange and correlation functionaland both the hybrid functionaland single $\mathrm{G}_{0} \mathrm{~W}_{0}$ reproducevalues close tothe experimental data.Conversely, an equivalent crystal field splitting $\Delta_{c r}=H H$ - $C H$ is obtainedfor PBE and HSEandthe value of InAscompares well with the self-consistent GW calculationof Zanoliet al. ${ }^{12,13} \mathrm{~A}$ similar behavior between PBE and HSE for $\Delta_{c r}$ under deformation is evidenced both for biaxial strain $\varepsilon_{\perp}$ and for uniaxial strain $\varepsilon_{z z}$ as shown in Fig.2. As definition, $\varepsilon_{\perp}=$ $\left(\varepsilon_{x x+} \varepsilon_{y y}\right)$ and $\varepsilon_{z z}$ stand for the strain components in and perpendicular of the $c$-plane. In the calculations, the internal parameter $u$ was fully relaxed for each strain. Anonlinear behavior is observed for the two semiconductorswhichcan be interpolatedwitha polynomial regression. It should be noted that (Fig. 2b) HSE exhibits a strong nonlinearity for the crystal field splitting of InAs even for moderate biaxial strain.

Theelectronic deformation potentials are defined as the linear coefficients in the expansion of the k.p band energies with respect to strain. Weinterpolatedthe present first-principle calculationsfor small deformationswith a derivation ofDPs from a $3 \times 3$ band k.p model ${ }^{25}$ which gives the linear dependence of $E_{A / B}$ and $E_{C}$ on strain as:

$$
\begin{gathered}
E_{A / B}=E_{A / B}(0)+\left(a_{c z}-D_{1}\right) \varepsilon_{z Z}+\left(a_{c t}-D_{2}\right) \varepsilon_{\perp}-\left(D_{3} \varepsilon_{z z}+D_{4} \varepsilon_{\perp}\right) \\
E_{C}=E_{C}(0)+\left(a_{c z}-D_{1}\right) \varepsilon_{z z}+\left(a_{c t}-D_{2}\right) \varepsilon_{\perp}
\end{gathered}
$$

$\left(a_{c z}, a_{c t}\right)$ and $\left(D_{1}, \quad D_{2}, D_{3}, D_{4}\right)$ characterize thedeformation potentialsof $\Gamma_{1 c}$ and $\Gamma_{1 v}$ and $\Gamma_{6 v}$ respectively. These relations are compatible with hexagonal symmetry $C_{6 v}$. On the other hand, the breaking of symmetry $C_{6 v}$ to orthorhombic $C_{2 v}$ with in-plane anisotropic strain lifts the degeneracy of $H H$ and $L H$ levels as:

$$
\Delta E=\left|E_{H H}-E_{C H}\right|=2\left|D_{5}\left(\varepsilon_{x x}-\varepsilon_{y y}\right)\right|
$$

The electronic deformation potentials of WZ InAs and InPare listed in table II.Differences are 
evidenced between PBE, $\mathrm{G}_{0} \mathrm{~W}_{0}$, and HSE. However, the calculations ensure an overall uniform behavior for the DPsincreasingdistinctly from InAs to InP.This trend with the band-gap has beenalso observed in group III-nitrides ${ }^{20}$ and group II-oxides. ${ }^{21}$ Moreover, the band-gap-related deformation potentialsof $a_{c z}-D_{1}$ and $a_{c t}-D_{2}$ are found more sensitive to exchange correlation functionalthan $D_{3}, D_{4}$ and $D_{5}$. Because there is currently no available experimental information and in order to gain insight into the quality of our simulations, we performed DP simulationsin ZB InAs and InP as a test. By comparison to our previous DFT-LDA calculations ${ }^{26}$,HSE-based calculations lead to a better agreement with experiment.The same conclusion is drawn from our present GGA computation. This gives us confidence in the ability of the hybrid functional to model deformation potentialsin wurtzite III-V semiconductors.Finally, the QC approximation wastested for InAs and InP from HSE results. The QC approximation is extensively used in k.pHamiltonians and based on a similar local atomic coordination between $\mathrm{WZ}$ and $\mathrm{ZB}$ crystals leading to a correlation of their physical properties along the [111] direction of the zinc-blende. Herein, we evaluated the deviation from the QC approximation of deformation potentials.Indeed, the same approximation in k.p theorylead to: $D_{3}+2 D_{4}=0$ and $D_{1}+D_{3}=D_{2}$. Actually, neither for InAs nor InPsatisfiedthese equations.For instance the first one yields- $0.93 \mathrm{eV}$ forInP and the failure must be related to the nonideal $c / a$ ratio.

As a conclusion, a systematic study of the electronic band structure in wurtziteInAsand InP is presented. Hybrid-functional calculations allow for a realistic description of the strained band energies. From accurate calculations of the electronic deformation potentials, we found the widely used QC approximation is not fulfilledfor both InAs and InP. We demonstrated that the dependence of electronic bands on strain is strongly nonlinear and it should be taken into account for a proper modeling of InAs/InP nanowire-based devices.

This work was performed using HPC resources from GENCI CINES and IDRIS 2013-2013096724. 
The work is supported through the participation of the INSCOOP ANR project 
Figure captions.
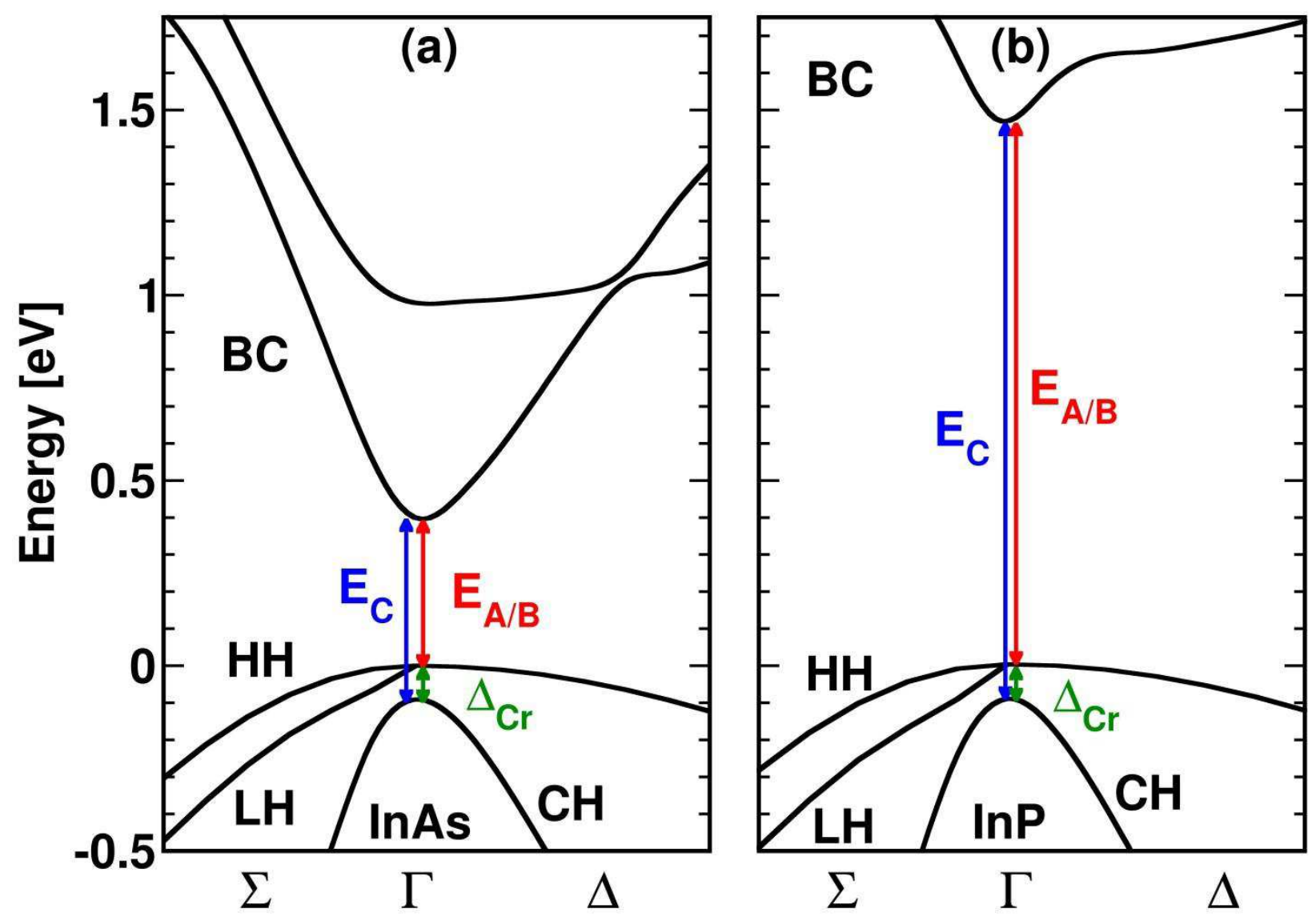

Figure 1: Blow-up of the WZ-InAs (a) and WZ-InP (b) band structurescalculated with HSEclose to the $\Gamma$ point. $\Sigma$ and $\Delta$ denote the in-plane and parallel directions with respect toc-axis. The origin of the energy scale is taken at the top of the valence band (VBM). 

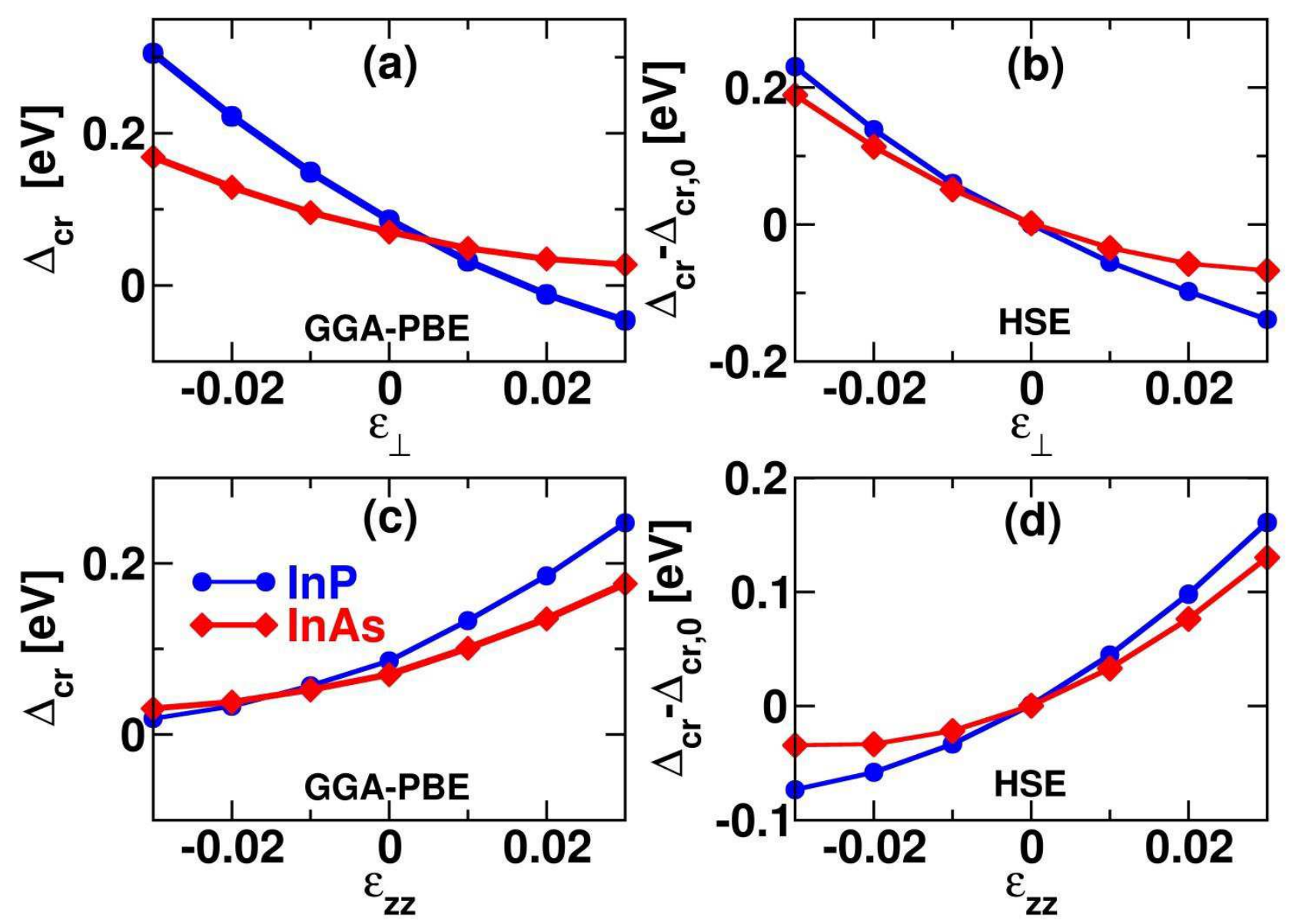

Figure 2: Left Panel:GGA-PBE dependence of the crystal-field splitting $\Delta_{c r}(\varepsilon)$ of InAs and InPon (a) in-plane and(c) perpendicular strain with respect to the c-plane. Right Panel: Dependence of $\Delta_{c r}(\varepsilon)-\Delta_{c r}(0)$ on (b) in-planeand(d) perpendicular straincalculated with HSE for InAs and InP. Quantization axis $\mathrm{z}$ is along the[0001] WZ direction. 


\section{Tables.}

Table I:Results of GGA-PBE, HSE, and $\mathrm{G}_{0} \mathrm{~W}_{0}$ calculations forwurtziteInAs and InP at equilibrium for the lattice constants $(a, c)$, internal parameter $u$, direct band gap $E_{A / B}$, crystal-field splitting $\Delta_{c r}$, and compared with the experimental values ${ }^{2,14,27}$ (Expt.).Single $\mathrm{G}_{0} \mathrm{~W}_{0}$ is performed on top of GGA calculations with identical structural parameters of GGA-PBE.

\begin{tabular}{|c|c|c|c|c|c|c|}
\hline & Method & $a(\AA)$ & $c(\AA)$ & $u$ & $E_{A / B}(\mathrm{eV})$ & $\Delta_{c r}(\mathrm{eV})$ \\
\hline \multirow[t]{4}{*}{$\mathrm{InP}$} & PBE & 4.229 & 6.881 & 0.3776 & 0.67 & 0.086 \\
\hline & $\mathrm{G}_{0} \mathrm{~W}_{0}$ & & & & 1.43 & 0.090 \\
\hline & HSE & 4.174 & 6.824 & 0.3742 & 1.47 & 0.093 \\
\hline & Expt. & $4.150^{\mathrm{a}}$ & $6.777^{\mathrm{a}}$ & - & $1.49^{\mathrm{a}}$ & - \\
\hline \multirow[t]{4}{*}{ In As } & PBE & 4.426 & 7.164 & 0.3817 & -0.31 & 0.070 \\
\hline & $\mathrm{G}_{0} \mathrm{~W}_{0}$ & & & & 0.42 & 0.088 \\
\hline & HSE & 4.330 & 7.066 & 0.3756 & 0.40 & 0.091 \\
\hline & Expt. & $4.283^{\mathrm{b}}$ & $6.995^{\mathrm{b}}$ & $0.3750^{\mathrm{b}}$ & $0.52^{\mathrm{c}}$ & - \\
\hline
\end{tabular}


Table II: Deformation potentials (eV) of wurtziteInAs and InP obtained with GGA-PBE, $\mathrm{G}_{0} \mathrm{~W}_{0}$, and HSE.

\begin{tabular}{ccccccc}
\hline \hline & Method & $a_{c z}-D_{1}$ & $a_{c t}-D_{2}$ & $D_{3}$ & $D_{4}$ & $D_{5}$ \\
\hline InAs & PBE & -3.67 & -5.31 & 4.70 & -2.18 & -2.21 \\
& $\mathrm{G}_{0} \mathrm{~W}_{0}$ & -3.06 & -6.12 & 5.62 & -2.77 & -2.63 \\
& $\mathrm{HSE}$ & -2.69 & -8.33 & 5.85 & -3.17 & -2.78 \\
& $\mathrm{PBE}$ & -3.13 & -7.20 & 5.55 & -3.09 & -2.84 \\
$\mathrm{InP}$ & $\mathrm{G}$ & -3.98 & -7.43 & 5.67 & -3.15 & -2.88 \\
& $\mathrm{G} \mathrm{W}_{0}$ & -4.05 & -7.64 & 5.92 & -3.28 & -2.94 \\
& $\mathrm{HSE}$ & & & & & \\
\hline \hline
\end{tabular}




\section{References}

${ }^{1}$ F. Qian, Y. Li, S. Gradecak, H.G. Park, Y. Dong, Y. Ding, Z.L. Wang, and C.M. Lieber Nano Lett. 5, 2287 (2005).

${ }^{2}$ J. Bao, D. C. Bell, F. Capasso, N. Erdman, D. Wei, L. Froberg, T. Martensson, and L. Samuelson, Adv. Mater. 21, 3654 (2009).

${ }^{3}$ Y. Li, F. Qian, J. Xiang, and C. M. Lieber, Nature 441, 489 (2006).

${ }^{4}$ C. Thelander, P. Agarwal, S. Brongersma, J. Eymery, L. F. Feiner, A. Forchel, M. Scheffler, W. Riess, B. J. Ohlsson, U.Gösele, and L. Samuelson, Mater. Today 9, 28 (2006).

${ }^{5}$ X. Duan, Y. Huang, R. Agarwal, and C. M. Lieber, Nature 421, 241 (2003).

${ }^{6}$ M. H. Huang, S. Mao, H. Feick, H. Yan, Y. Wu, H. Kind, E. Weber, R. Russo, P. Yang, Science 292, 1897 (2001).

${ }^{7}$ Y. Cui , Q. Wei , H. Park, and C. M. Lieber, Science 293, 1289 (2001).

${ }^{8}$ J. W. W. van Tilburg, R. E. Algra, W. G. G. Immink, M. Verheijen, E. P. A. M. Bakkers, and L. P. Kouwenhoven, Semicond. Sci. Technol. 25, 24011 (2010).

${ }^{9}$ M. H. HadjAlouane, R. Anufriev, N. Chauvin, H. Khmissi, K. Naji, B. Ilahi, H. Maaref, G. Patriarche, M. Gendry, and C. Bru-Chevallier, Nanotechnology 22, 405702 (2011).

${ }^{10}$ M.H. HadjAlouane, N. Chauvin, H. Khmissi, K. Naji, B. Ilahi, H. Maaref, G. Patriarche, M. Gendry, and C. BruChevallier, Nanotechnology24, 035704 (2013).

${ }^{11}$ F. Glas, J-C. Harmand, and G. Patriarche, Phys. Rev. Lett.99, 146101 (2007).

${ }^{12}$ I. Vurgaftman, J. R. Meyer, and L. R. Ram-Mohan, J. Appl. Phys. 89, 5815 (2001).

${ }^{13}$ Z. Zanolli, F. Fuchs, J. Furthmüller, U. von Barth, and F. Bechstedt, Phys. Rev. B 75, 245121 (2007).

${ }^{14}$ Z. Zanolli, M.-E. Pistol, L. E. Froberg, and L. Samuelson, J. Phys.: condens. Matter 19, 295219 (2007).

${ }^{15}$ J.Even, Appl. Phys. Lett.94, 102105 (2009).

${ }^{16}$ L. Pedesseau, C. Katan, and J.Even, Appl. Phys. Lett.100, 031903 (2012).

${ }^{17}$ G. Kresse and J. Furthmüller, Phys. Rev. B 54, 11169 (1996).

${ }^{18}$ J. Heyd, G. E. Scuseria, and M. Ernzerhof, J. Chem. Phys. 118, 8207 (2003).

${ }^{19}$ J. Heyd, G. E. Scuseria, and M. Ernzerhof, J. Chem. Phys. 124, 219906 (2006).

${ }^{20}$ Q. Yan, P. Rinke, M. Scheffler, and C. G. Van de Walle, Appl. Phys. Lett. 95, 121111 (2009).

${ }^{21}$ Q. Yan, P. Rinke, M. Winkelnkemper, A. Qteish, D. Bimberg, M. Scheffler, and C. G. Van de Walle, Appl. Phys. Lett. 101, 152105 (2012).

${ }^{22}$ J. P. Perdew, K. Burke, and M. Ernzerhof, Phys. Rev. Lett. 77, 3865 (1996).

${ }^{23}$ P. Haas, F. Tran, and P. Blaha, Phys. Rev. B 79, 85104 (2009).

${ }^{24}$ A. De and Craig E. Pryor, Phys. Rev. B 81, 155210 (2010).

${ }^{25}$ S. L. Chuang and C. S. Chang, Phys. Rev. B 54, 2491 (1996).

${ }^{26}$ L Pedesseau, J Even, A Bondi, W Guo, S Richard, H Folliot, C Labbe, C Cornet, O Dehaese, A Le Corre, O Durand and S. Loualiche, J. Phys. D 41, 165505 (2008)

${ }^{27}$ J.-M. Jancu, K. Gauthron, L. Largeau, G. Patriarche, J.-C.Harmand, and P. Voisin, Appl. Phys. Lett. 97, 41910 (2010). 